\title{
Neonatal transport in resource restricted settings: a simple clinical score at arrival and its role in predicting mortality
}

\author{
Deepak Rathod, Bethou Adhisivam", Vishnu Bhat \\ From International Summit on Emergency Medicine and Trauma 2014 \\ Puducherry, India. 12-16 February 2014
}

\section{Objectives}

To describe the indications and mode of transport of extramural neonates to JIPMER NICU.

To qualify the condition of neonates at arrival using a simple clinical score.

To analyze the effect of this clinical score on outcome.

\section{Methods}

Setting: JIPMER, a tertiary care teaching hospital, south India.

Number of subjects: extramural neonates ( $<28$ days) transported to JIPMER NICU $(\mathrm{n}=303)$.

Study design: descriptive study.

Transport and clinical details were recorded at arrival to NICU and all neonates were evaluated using a simple clinical score - sick neonate score (SNS) as described below in Table 1 .

All neonates were followed up until discharge or expiry. To determine the association of clinical factors with outcome Chi-square and Fisher exact test were used. All statistical analyses were carried out at 5\% level of significance and $p$ value $<0.05$ was considered significant. To determine the cutoff value for the clinical score (SNS), receiver operated curve was plotted.

\section{Results}

Most of the neonates were transported by private ambulance (36\%), followed by taxi (29\%), bus (15\%), 108 service (11\%), two-wheeler (6\%) and auto (3\%). The indications of transport were sepsis (30.7\%), HIE $(17.5 \%)$ and respiratory distress (15.2\%). Among 60 expired neonates $76 \%$ were hypothermic. SNS $\leq 8$ predicted mortality. All the components of SNS significantly correlated with outcome (i.e) lower the score, poorer the outcome. Neonates transported by 108 services and private ambulances had better SNS and outcome compared to neonates transported by other modes of transport .

Table 1

\begin{tabular}{|c|c|c|c|}
\hline \multirow[t]{2}{*}{ Variable } & \multicolumn{3}{|c|}{ Score } \\
\hline & 0 & 1 & 2 \\
\hline Respiratory effort & Apnea or Grunting & Tachypnea (>60/min) with or without retractions. & Normal (40-60/min) \\
\hline Heart rate & Bradycardia asystole & Tachycardia ( >160/min) & Normal (100-160/min) \\
\hline Mean blood pressure $(\mathrm{mmHg})$ & $<30$ & $30-39$ & $>39$ \\
\hline Axillary temperature $\left({ }^{0} \mathrm{C}\right)$ & $<36$ & $36-36.5$ & $36.5-37.5$ \\
\hline Capillary filling time (secs) & $>5$ & $3-5$ & $<3$ \\
\hline Random blood sugar (mg/dl) & $<40$ & $40-60$ & $>60$ \\
\hline $\mathrm{SpO}_{2}$ (in room air) & $<85 \%$ & $85-92 \%$ & $>92 \%$ \\
\hline
\end{tabular}

\footnotetext{
* Correspondence: Adhisivam1975@yahoo.co.uk

Department of Paediatrics, Jawaharlal Institute of Postgraduate Medical

Education and Research, Puducherry, India
}

C 2014 Rathod et al; licensee Springer This is an Open Access article distributed under the terms of the Creative Commons Attribution License (http://creativecommons.org/licenses/by/2.0), which permits unrestricted use, distribution, and reproduction in any medium, provided the original work is properly credited. 


\section{Limitations}

No pretransport score was available.

\section{Conclusion}

Neonatal transport in the region is not satisfactory and SNS is a useful clinical score for predicting mortality.

Published: 25 July 2014

\section{doi:10.1186/1865-1380-7-S1-P2}

Cite this article as: Rathod et al:: Neonatal transport in resource restricted settings: a simple clinical score at arrival and its role in predicting mortality. International Journal of Emergency Medicine 2014 7(Suppl 1):P2.

\section{Submit your manuscript to a SpringerOpen ${ }^{\circ}$ journal and benefit from:}

- Convenient online submission

- Rigorous peer review

- Immediate publication on acceptance

- Open access: articles freely available online

- High visibility within the field

- Retaining the copyright to your article 